\title{
Perforación del intestino delgado (yeyuno) como sospecha de manifestación extrapulmonar de COVID-19
}

\section{Small bowel (jejunal) perforation as a suspected extrapulmonary manifestation of COVID-19}

\author{
Oscar Enrique Guzmán-Del-Giudice. ', \\ Javier Ramón Targarona-Módena. ${ }^{2}$, \\ Elio Paul Lucchesi-Vásquez. ${ }^{3}$, \\ Miguel Trelles-de-Belaúnde., \\ Sebastián Javier Balarezo-Aguilar. ${ }^{5}$
}

Señor editor,

El SARS-CoV-2 (Síndrome respiratorio agudo severo relacionado a coronavirus 2) es un nuevo patógeno descubierto relacionado con la familia de los betacoronavirus. Su enfermedad se denominó COVID-19 (Enfermedad por coronavirus 2019). Se informó por primera vez en la ciudad de Wuhan, provincia de Hubei, República Democrática de China a fines de diciembre de 2019, y es el responsable de la pandemia actual declarada por OMS en marzo de 2020.

Al momento de escribir este artículo, los pacientes con COVID-19 informan en su mayoría manifestaciones respiratorias prominentes que incluyen fiebre, tos seca, disnea, etc.; pero, también aumenta la evidencia de manifestaciones extrapulmonares.

Presentamos el caso de una mujer de 81 años que acudió a nuestro servicio de urgencias por dos días de dolor abdominal en el cuadrante inferior izquierdo, vómitos, fiebre y malestar general. Negó migración del dolor, diarrea o síntomas respiratorios. La paciente tenía antecedentes de enfermedad celíaca, fibrilación auricular, hipertensión e insuficiencia renal crónica leve y estaba anticoagulada crónicamente con rivaroxaban.

A su arribo al triaje, los signos vitales fueron PA 77/49 mm $\mathrm{Hg}, \mathrm{FC} 134$ latidos/min, FR 18 respiraciones/min, T $37,5^{\circ} \mathrm{C}$

I. Médico adjunto. Servicio de Emergencia - Clínica Delgado, Lima, Perú

2. Doctor Cirujano adjunto. Clínica Delgado, Lima, Perú.

3. Médico emergencista. Servicio de Emergencia, Clínica Delgado, Lima, Perú.

4. Médico radiólogo. Departamento de Radiología, Clínica Delgado Lima, Perú.

5. Médico adjunto. Servicio de Emergencia, Clínica Delgado, Lima, Perú.
Guzmán-Del-Giudice O., Targarona-Módena J, Lucchesi-Vásquez E, Trelles-de-Belaúnde M y Balarezo-Aguilar S. Perforación del intestino delgado (yeyuno) como sospecha de manifestación extrapulmonar de COVID-1 9. Rev Soc Peru Med Interna. 2020;33(4): 198-200.

https://doi.org/10.36393/spmi.v33i4.573

$\mathrm{SatO}_{2} 95 \%$. Se la catalogó como choque séptico y fue llevada a la unidad de choque trauma bajo monitoreo; se iniciaron dos vías intravenosas, se le administró un bolo de suero fisiológico y se tomaron muestras de sangre para cultivo y laboratorio. El examen clínico mostró dolor a la palpación abdominal en el cuadrante inferior izquierdo y signos peritoneales. Se solicitó TEM abdominal con contraste y una consulta urgente a cirugía general. Los diagnósticos iniciales fueron: 1. Choque séptico versus hipovolémico 2. Abdomen agudo - abdomen agudo quirúrgico 3. Diverticulitis perforada/complicada versus trombosis mesentérica-isquémica versus emergencia aórtica. Los resultados de las pruebas de laboratorio relevantes fueron: leucocitosis con desviación a la izquierda (Leucocitos: 19040 células $/ \mathrm{mm}^{3}$, bastones células $/ \mathrm{mm}^{3}$ ), elevación en proteína $\mathrm{C}$ reactiva $(29,37 \mathrm{mg} / \mathrm{dl})$, procalcitonina $(3,61$ $\mathrm{ng} / \mathrm{ml})$, lactato $(2,4 \mathrm{mmol} / \mathrm{l})$ y creatinina sérica $(2,13 \mathrm{mg} /$ dl). La orden inicial de TEM contrastada se cambió a sin contraste debido a la creatinina elevada en 2,8 veces su valor anterior $(0,74 \mathrm{mg} / \mathrm{dl})$ y se incluyó orden de tórax debido a una preocupación secundaria por la pandemia en curso. La TEM mostró una colección intraabdominal de 4,5cm con nivel hidroaéreo y estriación grasa circundante, sugestivas de absceso secundario a perforación localizada del intestino delgado. No aire intraabdominal libre. También se identificó diverticulosis colónica sin signos de diverticulitis aguda. 

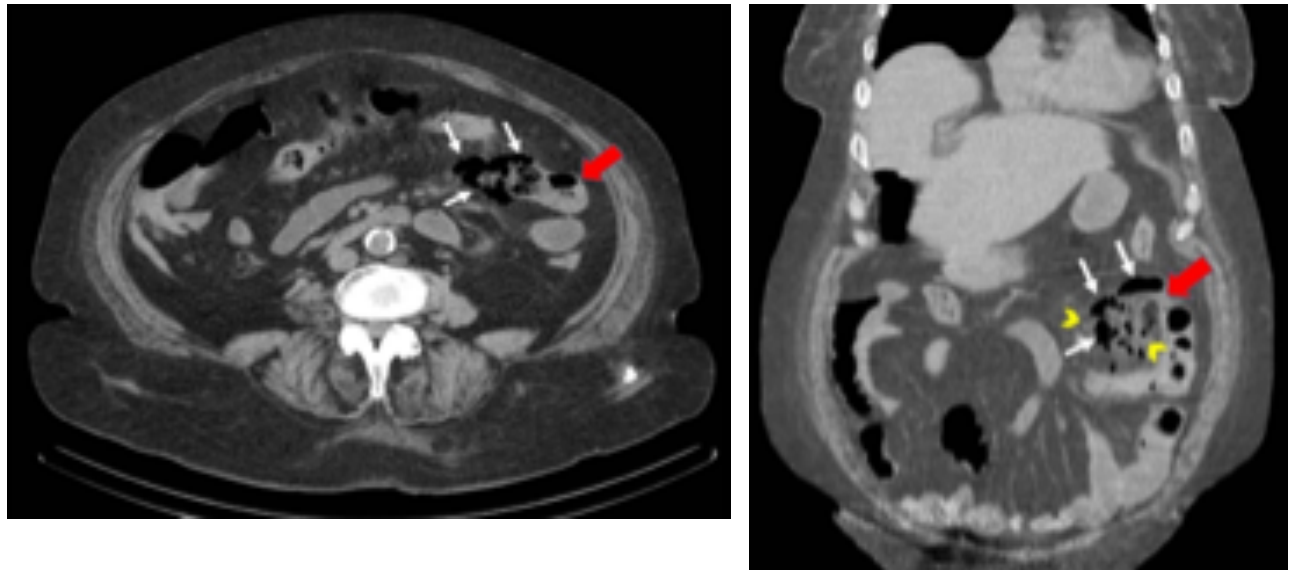

Imágenes I y 2. Tomografía computarizada abdominal sin contraste: Flecha roja y negrita: Intestino delgado. Flechas blancas: burbujas de aire libres. Puntas de flecha amarillas: estriación grasa.
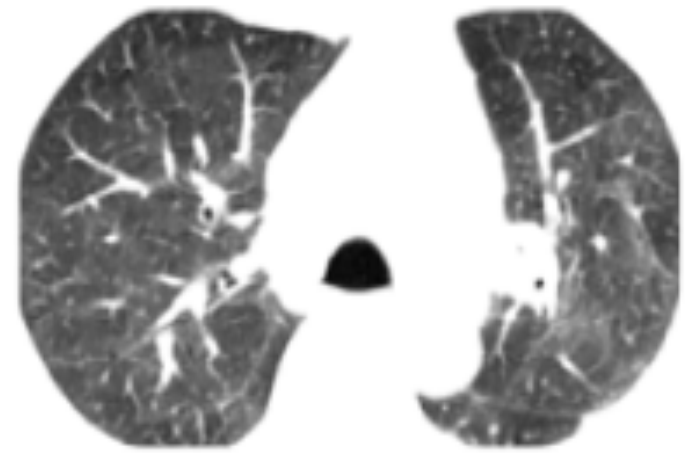

Imagen 3. Opacidades en vidrio esmerilado dominantes centrales bilaterales sobre los pulmones.
Los pulmones mostraban opacidades en vidrio esmerilado dominantes centrales bilaterales, indeterminados para el diagnóstico de neumonía por COVID-19. ${ }^{1}$ Ver informes completos e imágenes en el anexo. Se le inició antibióticos a la paciente, se tomó hisopado nasofaríngeo para rRT-PCR SARS-CoV-2 y se le preparó para una cirugía de emergencia. Se realizaron consultas a cirugía, hematología, cardiología y cuidados intensivos, y se envió la paciente al quirófano.

Durante la cirugía se identificó un plastrón sobre un segmento de yeyuno que mostraba microperforaciones inusuales en su lado mesentérico y burbujas de gas que se extendían hacia la raíz mesentérica correspondiente al área afectada observada en la TEM. Se resecó el asa de intestino delgado y se realizó una anastomosis laterolateral. Después
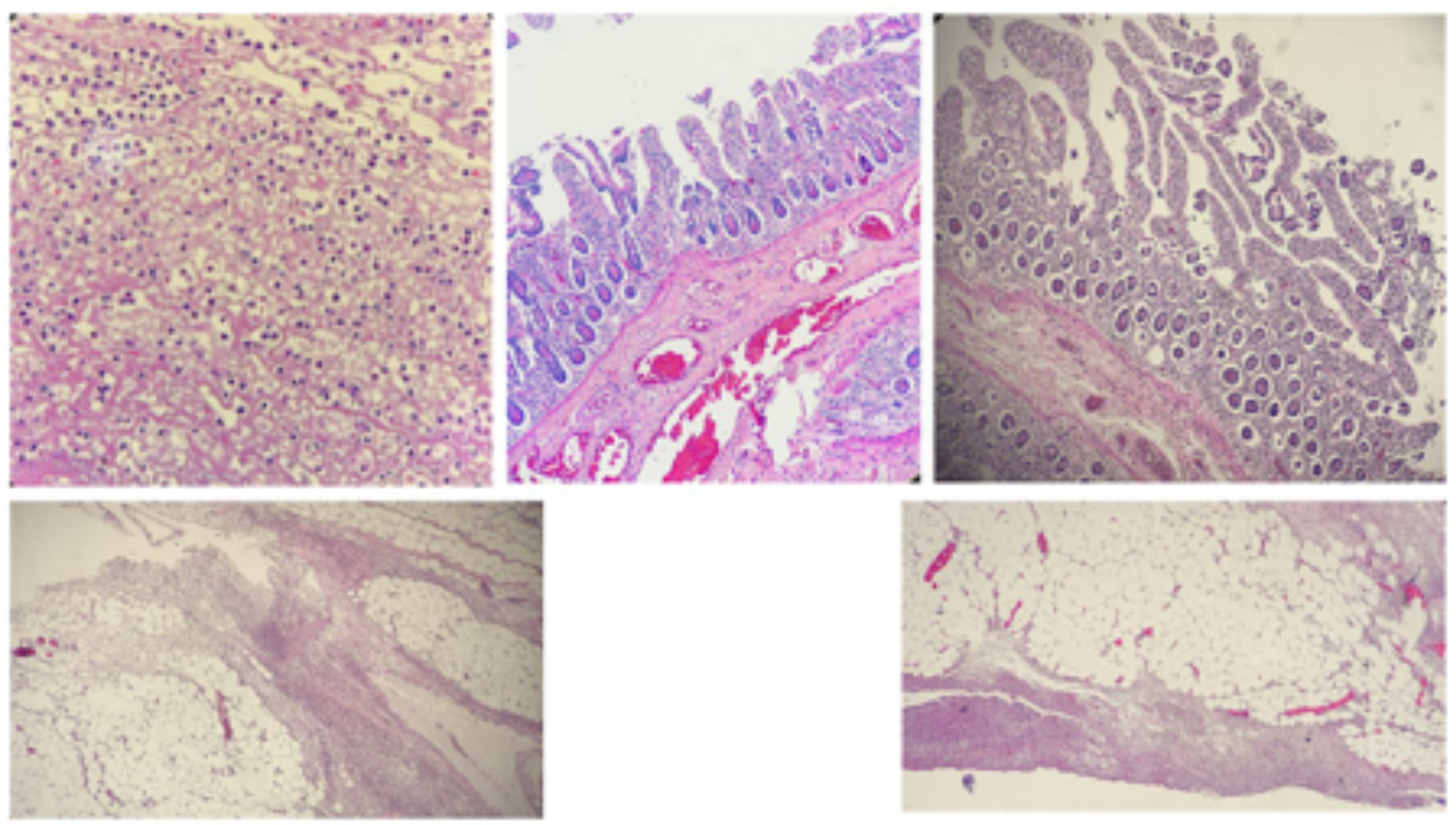

Imágnes 4a-4e. Necrosis yeyunal transmural asociada a mucosa intestinal erosiva con congestión vascular e infiltrado inflamatorio, principalmente por linfoplasmocitos. Serositis fibrinoleucocitaria grave y difusa. 
de la cirugía, la paciente fue ingresada en la UCI para manejo y apoyo, incluida la ventilación mecánica. Después de la cirugía, la prueba de PCR del SARS-CoV-2 se informó como positiva.

La patología reportó necrosis yeyunal transmural asociada a mucosa intestinal erosiva con congestión vascular einfiltrado inflamatorio, principalmente por linfoplasmocitos, serositis fibrinoleucocítica grave difusa, linfadenitis reactiva, bordes quirúrgicos sin evidencia de malignidad.

En China, hubo cuatro informes de casos de cirugía abdominal de emergencia altamente sospechosos de estar relacionados con COVID-19. Dos de ellos se debieron a perforación intestinal. ${ }^{2}$ Xiao $\mathrm{F}$. et al describieron que entre los 73 pacientes hospitalizados infectados con SARSCoV-2, 39 (53,42\%), incluidos 25 pacientes masculinos y 14 femeninos, dieron positivo al ARN del SARS-CoV-2 en las heces. Además, los datos de inmunofluorescencia mostraron que la proteína ACE2, que se ha demostrado ser un receptor celular del SARS-CoV-2, se expresa abundantemente en las células glandulares de los epitelios gástrico, duodenal y rectal, lo que favorece la entrada del SARS-CoV-2 en las células huésped. La detección del ARN del SARS-CoV-2 y la tinción intracelular de la proteína de la nucleocápside viral en el epitelio gástrico, duodenal y rectal demuestran que el SARS-CoV-2 infecta estas células epiteliales glandulares gastrointestinales. En la lámina propia del estómago, duodeno y recto se observaron numerosas células plasmáticas infiltrantes y linfocitos con edema intersticial. Se tomaron muestras de tejido mediante procedimientos de endoscopia alta y baja. Su informe incluyó pacientes hospitalizados del 1 al 14 de febrero de $2020 .^{3}$

Este es un caso probable de infarto mesentérico relacionado con COVID-19. En tiempos de pandemia, recomendamos estar al tanto de esta potencial complicación grave como manifestación extrapulmonar de COVID-19.

\section{REFERENCIAS BIBLOGRÁFICAS}

I. Simpson S, Kay FU, Abbara S, et al. Radiological Society of North America Expert Consensus Statement on Reporting Chest CT Findings Related to COVID-19. Endorsed by the Society of Thoracic Radiology, the American College of Radiology, and RSNA. J Thorac Imaging. 2020;2(2):e200 I52.

2. Gao Y, Xi H, Chen L. Emergency surgery in suspected COVID-I9 patients with acute abdomen: case series and perspectives. Ann Surg. 2020;272(I):e38-e39.

3. Xiao F, Tang M, Zheng X, Liu Y, Li X, Shan H. Evidence for Gastrointestinal Infection of SARS-CoV-2. Gastroenterology. 2020 May; I58(6): I83 I-I833.e3.

\section{CORRESPONDENCIA}

Oscar Enrique Guzmán-Del-Giudice

oguzman@auna.pe,dr.oscar.guzman@gmail.com

Fecha de recepción: 06-I I-2020.

Fecha de aceptación: 23-II-2020. 